\title{
Presence of very low density lipoprotein compositional abnormalities in Type 1 (insulin-dependent) diabetic patients; effects of blood glucose optimisation
}

\author{
A. Rivellese, G. Riccardi, G. Romano, R. Giacco, L.Patti, G. Marotta, G. Annuzzi and M. Mancini \\ Institute of Internal Medicine and Metabolic Diseases, University of Naples, Italy
}

Summary. Plasma lipoprotein compositional abnormalities were investigated in eight normolipidaemic (plasma cholesterol $<5.70 \mathrm{mmol} / \mathrm{l}$; triglyceride $<2.03 \mathrm{mmol} / \mathrm{l}$ ) young male Type 1 (insulin-dependent) diabetic patients (before and after a short period of optimised blood glucose control) and in nine healthy control subjects, matched for sex, age and body mass index. Free and esterified cholesterol, triglyceride, phospholipids were assayed in all lipoprotein classes (VLDL, IDL, LDL) and in HDL subclasses (HDL2 and HDL3); apoB was measured only in very low density lipoproteins (VLDL). All VLDL constituents were increased in the diabetic group, the differences being more striking for apoB $(6.0 \pm 1.1 \mathrm{mg} / \mathrm{dl}$ vs $2.0 \pm 0.1 \mathrm{mg} / \mathrm{dl}, p<0.02)$, free cholesterol $(0.27 \pm 0.04 \mathrm{mmol} / \mathrm{l}$ vs $0.13 \pm 0.02 \mathrm{mmol} / \mathrm{l}, p<0.02)$ and esterified cholesterol $(0.32 \pm 0.08 \mathrm{mmol} / 1$ vs $0.13 \pm 0.01 \mathrm{mmol} / 1, p<0.05)$. Also HDL subfractions showed differences between the two groups: all HDL2 constituents were increased, while in HDL3 only triglyceride was significantly increased $(0.11 \pm$ $0.01 \mathrm{mmol} / 1$ vs $0.08 \pm 0.004 \mathrm{mmol} / 1, p<0.02)$. After two weeks of optimised blood glucose control all VLDL consti- tuents were reduced and particularly: esterified cholesterol $(-39 \%, p<0.02)$, free cholesterol $(-37 \%, p<0.05)$, apoB $(-35 \%, p<0.05)$. Expressing each VLDL constituent as percent of the total lipoprotein mass, it was evident that the diabetic VLDL was rich in cholesterol both esterified $(8.4 \pm 1.0 \%$ vs $5.4 \pm 0.5 \%, p<0.02)$ and free $(8.5 \pm 0.7 \%$ vs $5.5 \pm 0.3 \%, \quad p<0.001)$, apo B $(5.1 \pm 0.6 \%$ vs $2.6 \pm 0.3 \%$, $p<0.001)$ and depleted in triglyceride $(57.0 \pm 1.7 \%$ vs $64.1 \pm 1.7 \%, p<0.001$ ). Two weeks of optimised blood glucose control were not able to correct the abnormal composition of VLDL. In conclusion, Type 1 (insulin-dependent) diabetic patients, although normolipidaemic, show an abnormal VLDL composition suggesting an increased prevalence of smaller and, possibly, more atherogenic VLDL particles. This abnormality is not corrected by a short period of blood glucose optimisation.

Key words: Lipoproteins, Type 1 (insulin-dependent) diabetes, blood glucose control, lipoprotein composition, atherosclerosis.
Atherosclerotic cardiovascular disease incidence and mortality are known to be increased in diabetic patients $[1,2]$. This is only partly explained by the major atherosclerosis risk factors which are present in some but not in all diabetic patients experiencing a major cardiovascular event $[1,3]$. In particular, an excess cardiovascular risk is reported in Type 1 (insulin-dependent) diabetic patients although in this category of patients plasma lipid concentrations are often normal [2,4]. This justifies the efforts to find out more subtle metabolic abnormalities which predispose Type 1 diabetic patients to atherosclerosis.

Recently, it has been proposed that not only gross elevations of plasma lipid concentrations, but also faint abnormalities of lipoprotein composition should be considered as predictors of cardiovascular disease [5]. In particular, cholesterol rich VLDL lipoproteins have been shown to contribute to the process of atherosclerosis $[6,7]$.

Therefore, we have undertaken this study in order to evaluate the plasma lipoprotein composition in a group of normolipidaemic young male Type 1 diabetic patients. Hyperlipidaemic patients have been excluded since the hyperlipidaemic status has, per se, profound effects on plasma lipoprotein composition [8]. Moreover, we have investigated in these patients the effects of a short period of optimisation of blood glucose control on plasma lipoprotein composition. 
Table 1. Clinical features of the participants $(M \pm S E M)$

\begin{tabular}{lll}
\hline & $\begin{array}{l}\text { Type 1 (insulin- } \\
\text { dependent) } \\
\text { diabetic patients } \\
(n=8)\end{array}$ & $\begin{array}{l}\text { Control } \\
\text { subjects }\end{array}$ \\
\hline Sex & male & male \\
Age (years) & $28.2 \pm 2.6$ & $28.7 \pm 2.4$ \\
Body mass index $(\mathrm{kg} / \mathrm{m} 2)$ & $22.6 \pm 0.8$ & $24.0 \pm 0.7$ \\
Diabetes duration (years) & $6.9 \pm 1.0$ & - \\
Plasma cholesterol (mmol/1) & $4.47 \pm 0.002$ & $4.05 \pm 0.16$ \\
Plasma triglyceride (mmol/1) & $1.38 \pm 0.22$ & $1.02 \pm 0.09$ \\
\hline
\end{tabular}

VLDL

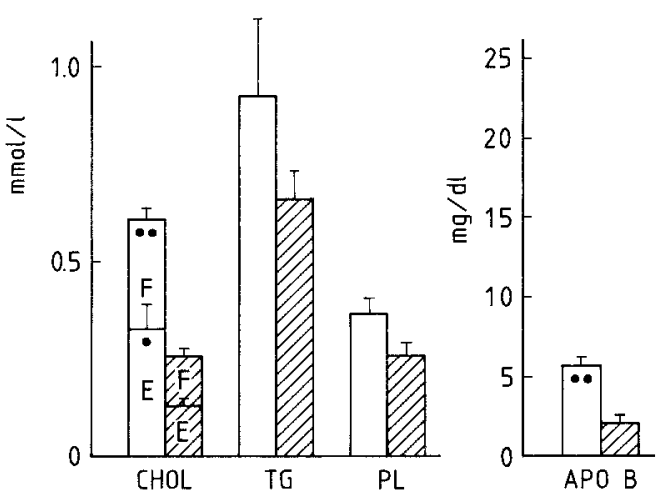

Fig. 1. VLDL lipid and apoB concentrations in a group of young male normolipidaemic Type 1 (insulin-dependent) diabetic patients ( $\square$ ) and in sex, age and BMI matched control subjects (Z). The results are expressed as mean \pm SEM. Significance vs control subjects: $\bullet p<0.05 ; \cdots p<0.02$. Abbreviations: $\mathrm{CHOL}=$ cholesterol; $\mathrm{F}=$ free; $\mathrm{E}=$ esterified; $\mathrm{TG}=$ triglyceride; $\mathrm{PL}=$ phospholipids

\section{Subjects and methods}

\section{Patients}

Eight young male patients with Type 1 (C-peptide negative) diabetes mellitus [9] participated in the study after giving their informed consent. They were recruited from our diabetic clinic on the basis of their blood glucose control (HbA1 $>10 \%$ during the last 3-6 months) and plasma lipid values (Cholesterol $<5.70 \mathrm{mmol} / 1$; Triglyceride $<2.03 \mathrm{mmol} / \mathrm{l})$. The main characteristics of the patients and their prestudy lipid levels are shown in Table 1 . They were all treated with long or intermediate acting + regular insulins twice daily. Two patients had background retinopathy, but none had clinically manifest nephropathy (urinary protein greater than $0.5 \mathrm{~g} / 24 \mathrm{~h}$ and/or glomerular filtration $<80 \mathrm{ml} / \mathrm{min}$ ) or any other disease known to influence lipid metabolism. None of the patients was taking medications other than insulin.

Nine normolipidaemic healthy males, matched with patients for age and body mass index (BMI), volunteered to participate in the study as control subjects. Some relevant features of these subjects are listed in Table 1.

\section{Study protocol}

Type 1 diabetic patients were hospitalised and continued throughout the study to follow their habitual isoenergetic diet (CHO $53 \%$, fat $30 \%$, protein $17 \%$, fibre $35 \mathrm{~g}$ ) and their usual physical activity.
After a period of one week to get accustomed to the hospital life, they underwent the baseline lipoprotein assessment. Thereafter, an intensified insulin treatment was started in the attempt to achieve a near normal blood glucose control as soon as possible (within 2-4 days).

Insulin was given by conventional means as regular insulin before breakfast and lunch and as a mixture of regular + intermediate insulin before dinner.

\section{Methods}

Blood glucose was measured daily in the fasting state as well as before and $2 \mathrm{~h}$ after lunch and dinner on capillary blood, drawn by finger stick, using the dextrostix glucometer system (Miles Laboratory, Italy). Total glycosylated haemoglobin (labile + stable) was measured at baseline and after two weeks of optimised control by ion-exchange chromatography using prepacked microcolumns (Bio-Rad, Richmond, California, USA) [10]. Normal values in our laboratory are $<8 \%$ with an interassay coefficient of variation of $2.8 \pm 0.2 \%$.

At baseline (on two subsequent days) and after two weeks of optimised control, samples for lipoprotein analysis were drawn without stasis in the morning-after an overnight fast with the patient in the recumbent position. After centrifugation, serum, additioned with merthiolate (final concentration 0.01\%), EDTA disodium salt and sodium azide (final concentration $0.05 \%$ ), was stored at $4^{\circ} \mathrm{C}$ for lipoprotein analysis, which was performed within one week.

Total serum and all lipoprotein classes were assayed for their cholesterol, both free and total, triglyceride and phospholipid content by commercially available enzymatic methods (Boehringer Biochemia Robin Mannheim, West Germany [11-14]. Esterified cholesterol was calculated as the difference between total and free cholesterol. ApoB in VLDL was measured in a single run by an immunoenzymatic method (Elisa) [15]. The intrassay coefficient of variation for apoB on VLDL was $4 \%$. Our laboratory participates in an international program for lipid quality control in connection with the Prague Reference Center of WHO [16].

For lipoprotein separation serum was firstly centrifuged (Beckman L5-65 with a fixed angle rotor $50.3 \mathrm{Ti}$ ) at a density of $1.006 \mathrm{~g} / \mathrm{ml}$ $\left(\right.$ EDTA saline $=1.006 \mathrm{~g} / \mathrm{ml}$ ) for $16 \mathrm{~h}$ at $40,000 \mathrm{rpm}$ and at $16^{\circ} \mathrm{C}$ to separate VLDL [17]. The bottom fraction was then adjusted to the density of $1.019 \mathrm{~g} / \mathrm{ml}$ and IDL was separated after a centrifugation for $18 \mathrm{~h}$ at $40,000 \mathrm{rpm}$ and at $16^{\circ} \mathrm{C}$ [17]. LDL in the infranate was separated from HDL by precipitation using a combination of dextran sulfate $500(20 \mathrm{~g} / \mathrm{l})$ and magnesium chloride $(2 \mathrm{~mol} / \mathrm{l})[18,19]$. For HDL3 separation serum density was increased at $\mathrm{d}=1.125 \mathrm{~g} / \mathrm{ml}$ and centrifuged for $48 \mathrm{~h}$ at $40,000 \mathrm{rpm}$ and at $16^{\circ} \mathrm{C}$. HDL2 lipid concentration was calculated as difference between total HDL and HDL3 concentration [20]. Recovery of total cholesterol, free cholesterol, triglyceride and phospholipids in lipoprotein fractions were respectively $104 \pm 4 \%, 93 \pm 3 \%, 103 \pm 4 \%, 99 \pm 4 \%$ ). Interassay coefficient of variation ranged for trigylceride from $2.6 \%$ (IDL) to $4.1 \%$ (total HDL); for total cholesterol from $2.0 \%$ (HDL3) to $6.9 \%$ (IDL); for free cholesterol from $2.4 \%$ (IDL) to $5.6 \%$ (VLDL, HDL3); for phospholipids from $2.7 \%$ (VLDL) to $4.0 \%$ (total HDL)

\section{Statistical analysis}

Values in the text are given as mean \pm SEM. At baseline, lipoproteins were measured in Type 1 diabetic patients and control subjects on two samples taken on subsequent days. Each value represents the average for the two days.

Statistical evaluation was performed according to standard procedures. In particular, the paired and unpaired t-test were utilised [21]. The level of statistical significance was set at $p<0.05$ for a two-tailed distribution. Log transformation was employed when appropriate (triglyceride). 


\section{Results}

The composition of the different lipoprotein classes in young normolipidaemic male Type 1 diabetic patients and in age, sex and BMI matched control subjects is reported in Figures 1-3. All VLDL constituents were increased in the diabetic group; however, the differences were more striking for apoB $(6.0 \pm 1.1$ vs $2.0 \pm$ $0.1 \mathrm{mg} / \mathrm{dl}, p<0.02)$, free cholesterol $(0.27 \pm 0.04 \mathrm{mmol} / 1$ vs $0.13 \pm 0.02 \mathrm{mmol} / 1), p<0.02)$ and esterified cholesterol $(0.32 \pm 0.08 \mathrm{mmol} / 1$ vs $0.13 \pm 0.01 \mathrm{mmol} / \mathrm{l}$, $p<0.05)$ while for triglyceride $(0.91 \pm 0.20 \mathrm{mmol} / \mathrm{l}$ vs $0.64 \pm 0.08 \mathrm{mmol} / \mathrm{l})$ and phospholipids $(0.38 \pm$ $0.09 \mathrm{mmol} / 1$ vs $0.25 \pm 0.09 \mathrm{mmol} / 1$ ) the differences $\mathrm{did}$ not reach the conventional level of statistical significance.

Also, the HDL subfractions were different in the two groups: all HDL2 components were increased in Type 1 diabetic patients, the difference being more evident for esterified cholesterol $(0.45 \pm 0.03 \mathrm{mmol} / 1 \mathrm{vs}$ $0.35 \pm 0.02 \mathrm{mmol} / 1, p<0.02$ ). In HDL3, only triglyceride was significantly increased in the diabetic group $(0.11 \pm 0.01 \mathrm{mmol} / 1$ vs $0.08 \pm 0.004 \mathrm{mmol} / 1, p<0.02)$ (Fig. 2).

Both IDL and LDL showed no significant differences between diabetic patients and control subjects (Fig. 3).

After two weeks of intensified insulin treatment, all parameters of blood glucose control improved significantly reaching a near normal level (Table 2). This was achieved by splitting the insulin dosage in more injections during the day without major changes in the total amount of insulin administered daily $(39 \pm 6 \mathrm{U}$ vs $37 \pm 5 \mathrm{U})$.

After two weeks of optimised blood glucose control, all VLDL constituents were reduced. The reduction was maximal for cholesterol, both esterified $(-39 \%, p<0.02)$ and free $(-37 \%, p<0.05)$ and for apoB $(-35 \%, p<0.05)$. It was less impressive for triglyceride $(-25 \%, p<0.05)$ and phospholipids $(-23 \%$, ns). Conversely, all other lipoprotein classes were not modified to any significant extent by the short period of optimised blood glucose control.

In order to better evaluate the abnormalities of VLDL composition in Type 1 diabetic patients, each lipoprotein constituent was expressed as percent of the total lipoprotein mass (Table 3). Apoprotein Cs and apoprotein $\mathrm{E}$ were not considered since they were not measured in this study.

It is evident that the diabetic VLDL has an abnormal composition since it is enriched in esterified cholesterol $(8.4 \pm 1.0 \%$ vs $5.4 \pm 0.5 \%, p<0.02)$, free cholesterol $(8.5 \pm 0.7 \%$ vs $5.5 \pm 0.3 \%, p<0.001)$, apoB $(5.1 \pm 0.6 \%$ vs $2.6 \pm 0.3 \%, p<0.001)$ and depleted in triglyceride $(57.0 \pm 1.7 \%$ vs $64.2 \pm 1.7 \%, p<0.02)$. Two weeks of optimised blood glucose control were not able to correct the abnormal composition of VLDL which remained rich in cholesterol ester $(7.4 \pm 0.6 \%$ vs $5.4 \pm 0.5 \%$,

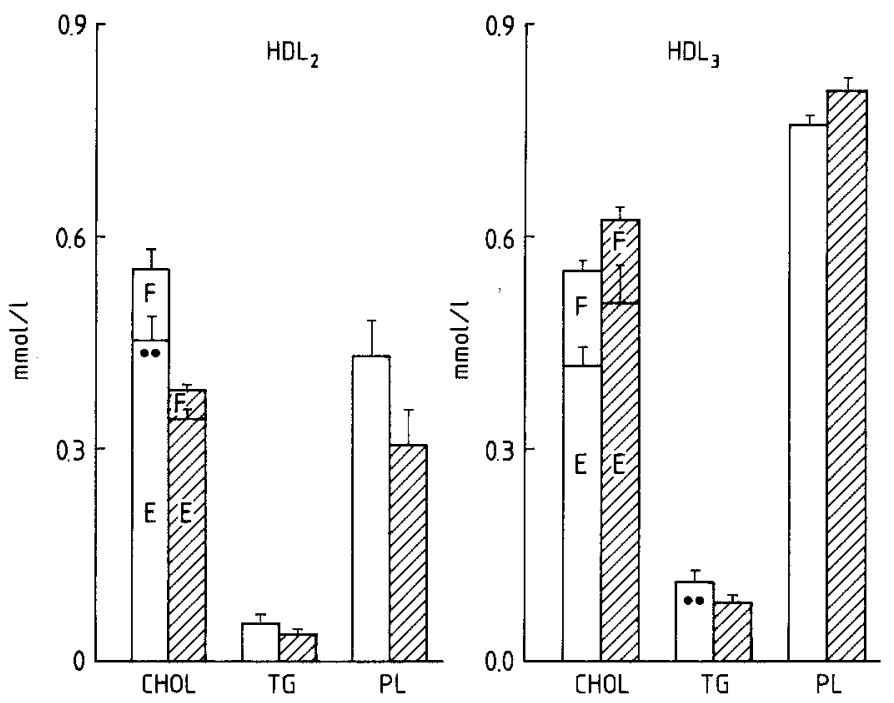

Fig. 2. HDL2 and HDL3 lipid concentrations in a group of young male normolipidaemic Type 1 diabetic patients $(\square)$ and in sex, age and BMI matched control subjects ( $\oslash)$. The results are expressed as mean \pm SEM. Significance vs control subjects: $\bullet p<0.02$ (Abbreviations see legend Figure 1)

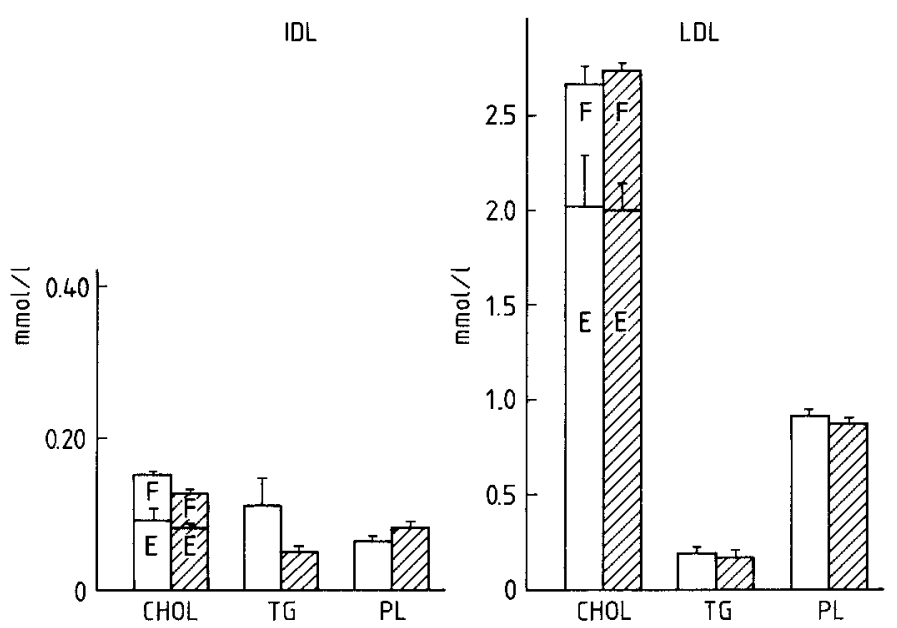

Fig. 3. IDL and LDL lipid concentrations in a group of young male normolipidemic Type 1 diabetic patients ( $\square$ ) and in sex, age and BMI matched control subjects ( $\square$ ). The results are expressed as mean \pm SEM. Abbreviations: see legend to Filgure 1

Table 2. Blood glucose (BG) control and daily insulin dosage in Type 1 (insulin-dependent) diabetic patients at baseline and after two weeks of optimised blood glucose control $(\mathrm{M} \pm \mathrm{SEM})$

\begin{tabular}{lcc}
\hline & Baseline & $\begin{array}{l}\text { Optimised } \\
\text { BG control }\end{array}$ \\
\hline $\begin{array}{l}\text { Fasting BG } \\
\text { (mmol/1) }\end{array}$ & $13.7 \pm 2.0$ & $6.9 \pm 1.0^{\mathrm{a}}$ \\
$\begin{array}{l}\text { 2 h post-prandial BG } \\
\text { (mmol/l) }\end{array}$ & $20.8 \pm 2.0$ & $6.8 \pm 1.3^{\mathrm{a}}$ \\
$\begin{array}{l}\text { Average daily BG } \\
\text { (mmol/1) }\end{array}$ & $16.0 \pm 0.8$ & $6.9 \pm 0.6^{\mathrm{a}}$ \\
$\begin{array}{l}\text { Total HbA1 } \\
(\%)\end{array}$ & $12.0 \pm 1.5$ & $9.8 \pm 1.6^{\mathrm{a}}$ \\
$\begin{array}{l}\text { Daily insulin dosage } \\
(\mathrm{U})\end{array}$ & $39.5 \pm 6.2$ & $36.7 \pm 5.0$ \\
\hline
\end{tabular}

${ }^{\mathrm{a}} p<0.001$ vs baseline 
Table 3. VLDL composition ${ }^{\mathrm{d}}$ in Type 1 (insulin-dependent) diabetic patients at baseline and after two weeks of optimised blood glucose control and in control subjects $(M \pm S E M)$

\begin{tabular}{|c|c|c|c|}
\hline & \multicolumn{2}{|c|}{$\begin{array}{l}\text { Diabetic patients } \\
(n=8)\end{array}$} & \multirow[t]{2}{*}{$\begin{array}{l}\text { Control subjects } \\
(n=9)\end{array}$} \\
\hline & Baseline & $\begin{array}{l}\text { Optimised } \\
\text { BG control }\end{array}$ & \\
\hline & $(\%)$ & $(\%)$ & $(\%)$ \\
\hline ApoB & $5.1 \pm 0.6^{\mathrm{c}}$ & $6.3 \pm 1.6^{\mathrm{b}}$ & $2.6 \pm 0.3$ \\
\hline Free cholesterol & $8.5 \pm 0.7^{\mathrm{c}}$ & $6.6 \pm 0.7$ & $5.5 \pm 0.3$ \\
\hline Esterified cholesterol & $8.4 \pm 1.0^{b}$ & $7.4 \pm 0.6^{\mathrm{a}}$ & $5.4 \pm 0.5$ \\
\hline Triglyceride & $57.0 \pm 1.7^{\mathrm{b}}$ & $58.4 \pm 1.8^{\mathrm{a}}$ & $64.2 \pm 1.7$ \\
\hline Phospholipids & $21.0 \pm 1.0$ & $21.3 \pm 1.4$ & $22.2 \pm 1.3$ \\
\hline
\end{tabular}

${ }^{\mathrm{a}} p<0.05 ;{ }^{\mathrm{b}} p<0.002 ;{ }^{\mathrm{c}} p<0.001$ vs control subjects; ${ }^{\mathrm{d}}$ Each VLDL component is expressed as percentage of the total lipoprotein mass

$p<0.05)$ and apoB $(6.3 \pm 1.6 \%$ vs $2.6 \pm 0.3 \%, p<0.02)$ and depleted in triglyceride content $(58.5 \pm 1.8 \%$ vs $64.1 \pm 1.7 \%, p<0.05)$ in comparison with the control group.

\section{Discussion}

This study clearly demonstrates that in Type 1 diabetic patients abnormalities of VLDL composition exist which might be regarded as predisposing to atherosclerosis. These abnormalities were found despite the fact that all patients had normal plasma cholesterol and triglyceride levels. Furthermore, these abnormalities were not corrected by a short period of optimisation of blood glucose control. By contrast, in our group of Type 1 diabetic patients, other serum lipoproteins did not show major compositional abnormalities which might be considered atherogenetic.

Many studies have focused on lipoprotein metabolism in diabetic patients. In these studies, derangements of VLDL metabolism have been consistently demonstrated in patients with insulin-dependent diabetes $[4$, 22-24]. However, the interest has been, in general, limited to plasma VLDL concentrations without paying too much attention to the lipoprotein composition. The latter has become increasingly important once the evidence has been forwarded that abnormalities of VLDL composition might be related to the process of atherogenesis [5-7].

In the present study, the diabetic VLDL is enriched in cholesterol (both free and esterified) and apoB. For its composition, this lipoprotein closely resembles the VLDL remnant or $\beta$-VLDL which is able to produce cholesteryl ester deposition in macrophages and endotelial cells [6]. Moreover, in clinical studies cholesterol and apoB enriched VLDL, lipoproteins have been found to be associated with coronary and peripheral artery diseases [7].

Two weeks of blood glucose control optimisation reduced all VLDL constituents, but the relative contribution of each lipoprotein component to the overall VLDL mass remained unbalanced towards a cholesterol and apoB enrichment. This suggests that the optimisation of blood glucose control in Type 1 diabetic patients is able to reduce VLDL concentration but has no major influence on its composition. Of course, the short term nature of this study prevents one from drawing definitive conclusions on this aspect, but there are reasonable indications that, due to the rapid VLDL turnover rate, two weeks should be sufficient to reach a new steady state of VLDL metabolism [25]. Several studies have investigated the lipoprotein profile in Type 1 diabetic patients [4, 22-24], but no attempt has been made, so far, to evaluate the lipid composition of all lipoprotein classes including IDL and the HDL subfractions. We have investigated this aspect, but we did not find major compositional abnormalities in our Type 1 diabetic patients other than in VLDL. In particular, IDL and LDL concentration and composition were very similar in Type 1 diabetic patients and in normoglycaemic control subjects. This confirms that LDL metabolism is not deranged in Type 1 diabetic patients when insulin therapy is instituted [4, 23]. Although in our diabetic patients all HDL2 constituents were elevated, the overall HDL2 composition was similar to that found in normoglycaemic control subjects. Conversely, the HDL3 subfraction showed higher triglyceride levels in diabetic patients in comparison with the control group. Two weeks of blood glucose optimisation did not modify the concentration and the composition of these lipoproteins.

A metabolic interpretation of our findings is neither simple nor immediate. Three key metabolic processes regulate VLDL concentration and composition in the fasting state: (1) the hepatic synthesis, (2) the delipidation process activated by lipoprotein lipase, (3) the final catabolism through the metabolic cascade VLDL $\rightarrow$ $\mathrm{IDL} \rightarrow \mathrm{LDL}$ or by liver uptake.

VLDL synthetic rate has been reported to be normal in normolipidaemic Type 1 diabetic patients with a moderate degree of blood glucose control [26].

On the other hand, in this group of patients lipoprotein lipase is overstimulated by the elevated peripheral insulin levels [27]. Therefore, VLDL compositional abnormalities are, most likely, a consequence of the enhanced delipidation process regulated by lipoprotein lipase: the large, triglyceride enriched VLDL particles are readily transformed in smaller, denser, cholesterol and apoB enriched lipoproteins. The increased HDL plasma levels, which we have found in our group of patients, give further support to the hypothesis of an overactivation of lipoprotein lipase.

An alternative, although less plausible, explanation for the abnormal VLDL composition in Type 1 diabetic patients might be that in these patients the liver secretes an apoB VLDL that is relatively enriched with cholesterol.

In the presence of an abnormal lipoprotein, the limiting step of VLDL catabolism in Type 1 diabetic patients is the lipoprotein uptake at the liver level. In fact, 
the other VLDL catabolic pathway, represented by the metabolic cascade VLDL $\rightarrow \mathrm{IDL} \rightarrow \mathrm{LDL}$, is probably not impaired in these patients, as demonstrated by the IDL and LDL normal concentration and composition.

The liver uptake of VLDL is receptor-mediated and is influenced by the lipid and apoprotein composition of VLDL. The cholesterol enrichment of this lipoprotein might impair this key catabolic step, thus leading to the accumulation of small VLDL particles [28]. In addition, an abnormal pattern of apoE isophorms in VLDL, as reported in some studies in diabetic patients, is also able to impair the liver removal of this lipoprotein $[29,30]$.

The optimisation of blood glucose control reduces the VLDL synthetic rate to values below normal thus lowering the VLDL concentration [26]. However, it cannot modify the abnormal VLDL composition which is, in our opinion, in large part a consequence of the lipoprotein lipase overstimulation due to the high peripheral insulin levels [27].

In conclusion, VLDL compositional abnormalities are present in Type 1 diabetic patients even in absence of frank hyperlipidaemia and are not corrected by a short period of optimised blood glucose control. They might contribute to the increased risk for cardiovascular disease of this group of patients.

Acknowledgements. This study was supported, in part, by a grant from the University of Naples (Italy). We, gratefully, thank the King Gustaf V Research Institute, Karolinska Institute, Stockholm, Sweden for apolipoproteins determination.

\section{References}

1. Pan WH, Cedres LB, Lin K, Dyer A, Schoenharger JA, Shekelle RB, Stamler R, Smith D, Collette P, Stamler J (1986) Relationship of clinical diabetes and asymptomatic hyperglycemia to risk of coronary heart disease mortality in men and women. Am J Epidemiol 123: 504-516

2. Darmon JS, La Porta RE, Kuller LH, Cruickshanks KS, Orchard JJ, Wagner DK, Becker DJ, Cavender DE, Drash AL (1984) The Pittsburg insulin dependent diabetes mellitus (IDDM) morbidity and mortality study. Diabetes $33: 271-276$

3. Kannel WB, McGee DR (1979) Diabetes and cardiovascular risk factors. The Framingham study. Circulation 59: 8-13

4. Nikkila EA (1984) Plasma lipid and lipoprotein abnormalities in diabetes. In: Jarrett $\mathbf{J}$ (ed) Diabetes and heart disease. Elsevier, Amsterdam New York, pp 133-167

5. Ruderman NB, Haudenschild C (1984) Diabetes as an atherogenic factor. Prog Cardiovasc Dis 26: $373-411$

6. Mahley RW, Innerarity TL, Brown MS, Ho YK, Goldstein JL (1980) Cholesteryl ester synthesis in macrophages: stimulation by $\beta$-very low density lipoproteins from cholesterol-fed animals of several species. J Lipid Res 21: 970-980

7. Takami R, Mabuchi H, Ueda K, Ueda R, Haba T, Kametani T, Ito S, Koizumi J, Ohta M, Miyamoto S, Nakaiama A, Kanaya $H$, Oiwake H, Genda A, Takeda R (1981) Intermediate-density Lipoprotein and Cholesterol-rich very low density lipoprotein in angiographically determined coronary artery disease. Circulation 64: 1174-1184

8. Eisemberg S, Gavish D, Oschry Y, Fainary M, Deckelbaum RJ (1984) Abnormalities in very low, low, and high density lipoproteins in hypertriglyceridemia. J Clin Invest 74: 470-482

9. WHO Expert Committee on Diabetes Mellitus (1980) Second report. World Health Organization. Tech Rep Ser 646, Geneva, WHO
10. Trivelli LA, Ranney HM, Lai HT (1971) Hemoglobin components in patients with diabetes mellitus. N Engl J Med 824:353-356

11. Staehler F, Gruber W, Stinshoff K, Roeschlau P (1977) Eine praktischgerechte enzymatische Cholesterin-Bestimmung. Med Lab 30: $29-30$

12. Siedel J, Schlumberger H, Klose S, Ziegenhorn J, Wahlefeld AW (1981) Improved reagent for enzymatic determination of serum cholesterol. J Clin Chem Clin Biochem 19: 838-839

13. Wahlefeld AW (1974) Triglycerides determination after enzymatic hydrolysis. In: Bergmeyer HU (ed) Methods of enzymatic analysis, 2nd edn, Vol 4. Verlag Chemie, Weinheim, Academic Press, New York London, pp 1831-1974

14. Takaiama M, Itoh S, Nagasaki T, Tanimizu I (1977) A new enzymatic method for determination of serum choline containing phospholipids. Clin Chim Acta 79: 93-98

15. Holmquist L (1982) Quantitation of human serum apolipoprotein B by enzyme immunoassay. Clin Chim Acta 121:327-336

16. Grafnetter D (1977) World Health Organization (WHO) coordinated quality control in the lipid laboratory. Giorn Arterioscl 2: 113-128

17. Hatch FT, Lees RS (1968) Practical methods for plasma lipoprotein analysis. In: Paoletti R, Kritchevsky D (eds) Advances in lipid research, vol 6. Academic Press, New York, pp 1-68

18. Carlson K (1973) Lipoprotein fractionation. J Clin Pathol 26: [Suppl 5]: 32-37

19. Kostner GM (1976) Enzymatic determination of cholesterol in high density lipoprotein fractions prepared by polyanion precipitation. Clin Chem 22: 695-698

20. Kirstein P, Carlson K (1981) Determination of the cholesterol content of high density lipoprotein subfractions HDL2 and HDL3, without contamination of $\mathrm{Lp}(\mathrm{a})$, in human plasma. Clin Chim Acta 113: 123-134

21. Snedecor GW, Cochran WG (1980) Statistical methods, 7th edn. The Iowa State University Press, Ames, Iowa

22. Rubba P, Capaldo B, Falanga A, Caprio S, Rivellese A, Riccardi G, Mancini M (1985) Plasma lipoproteins and lipoprotein lipase in young diabetics with and without ketonuria. J Endocrinol Invest $8: 433-436$

23. Howard BV (1987) Lipoprotein metabolism in diabetes mellitus. J Lipid Res 28: 613-628

24. Lopez-Virella MF, Wohltmann HJ, Loadholt CB, Buse MG (1981) Plasma lipids and lipoproteins in young insulin-dependent diabetic patients: relationship with control. Diabetologia 21: 216-223

25. Zech LA, Grundy SM, Steinberg D, Berman M (1979) Kinetic model for production and metabolism of very low density lipoprotein triglycerides. J Clin Invest 63: 1262-1273

26. Pietri AO, Dunn FL, Grundy SM, Raskin P (1983) The effect of continuous subcutaneous insulin infusion on very-low-density lipoprotein triglyceride metabolism in Type I diabetes mellitus. Diabetes 32: 75-81

27. Nikkila EA, Harmila P (1978) Serum lipids and lipoprotein in insulin-treated diabetes. Diabetes 27:1078-1086

28. Kushwaha RS, Hazzard WR (1978) Catabolism of very low density lipoproteins in the rabbit. Effect of changing composition and pool size. Biochim Biophys Acta 528: 176-189

29. Weisweiler P, Jungst D, Schwandt P (1983) Quantitation of apolipoprotein E-isoforms in diabetes mellitus. Horm Metab Res 15: 201-204

30. Davignon J, Gregg RE, Sing CF (1988) Apolipoprotein E polymorphism and atherosclerosis. Arteriosclerosis 8:1-21

Received: 7 June 1988

and in revised form: 18 October 1988

Dr. A. Rivellese

Institute of Internal Medicine and Metabolic Diseases

2nd Medical School

University of Naples

Via S. Pansini 5

I-80131 Napoli

Italy 